\section{The iron method of haemoglobin estimation}

\author{
J. FINE From the Royal Gwent Hospital, \\ Newport, Mon.
}

Although the estimation of haemoglobin in blood by its iron content is admittedly the most accurate of the methods available in haemoglobinometry a simple procedure for carrying this out is not described in current textbooks.

The best-known technique for determining iron, described by King and Wootton (1956), involves the ashing of a known quantity of blood in a muffle furnace, the conversion of the iron in the ash to ferrous chloride, and a final titration with titanous chloride. Such a method is not likely to commend itself, either for speed or simplicity, to the smaller laboratory. A much simpler procedure consists in the separation of iron from the haemoglobin molecule by treatment with acid, and the subsequent conversion of the liberated iron into ferric thiocyanate, which is then estimated colorimetrically. A number of such methods have been published (Berman, 1918; Brown, 1922; Wong, 1923, 1928), all based on the same principle of iron separation and conversion to thiocyanate, but differing according to the acid used to effect separation. Another point of difference is the choice of the oxidizing agent employed to ensure conversion of the iron to the ferric state: without such oxidation a large proportion of the iron may remain in the ferrous state and would thus escape detection when treated with thiocyanate. A critical study of the published methods, though confirming their accuracy, has shown them to be unnecessarily elaborate, and the following procedure has been devised which enables a result to be obtained in about 15 minutes, with an error not exceeding $2 \%$, when samples of blood of known content supplied by the Medical Research Council were analysed.

REAGENTS

$1 \mathrm{H}_{2} \mathrm{SO}_{4}$, A.R.

2 Saturated potassium chlorate prepared by dissolving $10 \mathrm{~g}$. in $100 \mathrm{ml}$. distilled water with the aid of heat, allowing to cool and filtering.

$33 \mathrm{~N} \mathrm{KCNS}(29.7 \%)$

Received for publication 15 December 1960.
$410 \%$ sodium tungstate

5 Standard iron solution prepared as follows:Ferrous ammonium sulphate, $\mathbf{0 . 7} \mathrm{g}$., is dissolved in $\mathbf{1 0}$ $\mathrm{ml}$. distilled water. Then $5 \mathrm{ml}$. concentrated sulphuric acid is added and the mixture slightly warmed. N/10 potassium permanganate is added until oxidation of iron is complete, as indicated by a persisting permanganate tinge: about $15 \mathrm{ml}$. is required for this. Distilled water is then added up to one litre. This solution contains $\mathbf{0 \cdot 1}$ mg. iron in $1 \mathrm{ml}$.

\section{PROCEDURE}

1 To a test tube containing $2 \mathrm{ml}$. distilled water add $0.1 \mathrm{ml}$. blood, $0.4 \mathrm{ml}$. saturated potassium chlorate, and $0.4 \mathrm{ml}$. concentrated sulphuric acid.

2 Mix and place in a boiling water bath for five minutes.

3 Cool, add $0.4 \mathrm{ml} .10 \%$ sodium tungstate and mix, and transfer to a $10 \mathrm{ml}$. cylinder and make up to $10 \mathrm{ml}$. with distilled water.

4 Mix, stand for two minutes, and centrifuge.

5 Pour off the supernatant, pipette off $8 \mathrm{ml}$. and add $2 \mathrm{ml}$. 3N KCNS and read the optical density, using a green filter.

6 For the standard, pipette $0.4 \mathrm{ml}$. into a test tube and add $7 \mathrm{ml}$. distilled water, $0.6 \mathrm{ml}$. saturated potassium chlorate, and $2 \mathrm{ml}$. KCNS.

7 If extinctions of standard and unknown are $a$ and $b$ respectively

$$
\begin{aligned}
\text { then } \frac{a}{b} & =\frac{\text { iron content of standard }}{\text { iron content of unknown }} \\
\therefore \text { Fe content of unknown } & =\frac{b}{a} \times 0.04 \mathrm{mg} . \\
\text { Haemoglobin of unknown } & =\frac{\mathrm{b}}{\mathrm{a}} \times 0.04 \times 300 \mathrm{mg} . \\
\text { (assuming Fe } & =0.334 \% \text { of } \mathrm{Hb} \text { ) } \\
& =12 \frac{\mathrm{b}}{\mathrm{a}} \mathrm{mg} .
\end{aligned}
$$

Since unknown tube contained iron from $0.08 \mathrm{ml}$. blood, then haemoglobin content of blood $=\frac{b}{a} \times 12 \times \frac{10}{8}=$ $15 \frac{\mathrm{b}}{\mathrm{a}} \mathrm{g} \%$

\section{REFERENCES}

Berman, L. (1918). J. biol. Chem., 35, 231.

Brown, A. L. (1922). J. Amer. chem. Soc., 44, 423.

King, E. J., and Wootton, I. D. P. (1956). Micro-Analysis in Medical Biochemistry, 3rd ed., p. 32. Churchill, London.

Wong, S. Y. (1923). J. biol. Chem., 55, 421.

- (1928). Ibid., 77., 409. 